\title{
MACHADO DE ASSIS: PULSÃO DE MORTE EM O IMORTAL
}

\section{MACHADO DE ASSIS: DEATH PULSE IN THE IMMORTAL}

\author{
Vítor Castelões Gama ${ }^{1}$
}

DOI: 10.26512/aguaviva.v3i1.12206

Recebido em: 12 abr. 2018

Aceito em: 11 jun. 2018

RESUMO: Considerando o conto $O$ imortal de Machado de Assis, objetiva-se entender como as pulsões de vida e morte entram em conflito na psique do personagem imortal. Para tanto, observam-se os conceitos de Freud e André Green tanto em relação às teorias pulsionais quanto ao conceito de imortalidade. Conclui-se que a imortalidade do personagem é fruto de um desejo narcísico que, por fim, acaba imbricando ainda mais as pulsões, e que possui ramificação pelo ato de escrita.

Palavras-chave: Freud; Pulsão de Morte; André Green; Machado de Assis.

\begin{abstract}
Considering the tale The Immortal of Machado de Assis, we seek to understand how the life and death drives conflict within the psyche of the immortal character. For this, the concepts of Freud and André Green are observed both in relation to the theories of the pulsion and the concept of immortality. It is concluded that the immortality of the character is the fruit of a narcissistic desire that, in the end, ends up imbricating still more the drives, and entangling itself by the act of writing.
\end{abstract}

Keywords: Freud; Death Pulse; André Green; Machado de Assis.

"Não é possível olhar fixamente para o sol nem para a morte"

(La Rochefoucauld)

\footnotetext{
1 Doutorando pelo Programa de Pós-Graduação em Literatura e Práticas Sociais da Universidade de Brasília (PósLIT/UnB). Membro do Grupo de Pesquisa Psicologia e Literatura. E-mail: vitorcasteloesgama@hotmail.com
} 
Machado de Assis publicou o conto "O Imortal" na revista carioca "A Estação" entre julho e setembro de 1882. A história remete a um clima de fantasmagoria, onde três interlocutores reúnem-se para ouvir sobre a vida de um homem que, apesar de imortal, morreu. O narrador conhecido apenas como Dr. Leão, médico homeopata, relata a vida de seu pai Ruy de Leão para o Coronel Bertioga e o tabelião João Linhares.

Por conta da temática, confluências estéticas e teóricas com o conceito da pulsão de morte da psicanálise são sentidas no conto. Como ressalta Lionel Trilling (2015, p. 63) ler uma obra literária e passar para a teoria psicanalítica é mudar "de uma ordem de percepção a outra, mas a natureza da psicologia freudiana é exatamente o material sobre o qual os poetas têm sempre exercido sua arte. Não surpreende, portanto, que a teoria psicanalítica tenha tido grande efeito sobre a literatura". Cabe destacar que não interessa realizar uma análise psicológica do escritor, mas, analisar a obra. E, neste aspecto, há no mínimo duas maneiras:

Quer dizer, por um lado, parece estabelecer-se entre a Literatura e a Psicanálise uma relação aditiva em que se tenta acrescentar sentidos ao texto literário a partir da interpretação psicanalítica e por outro, vislumbra-se uma atitude que poderíamos chamar de extrativa, interessada em tentar resgatar do texto literário a particularidade que pudesse nutrir a Psicanálise (VILLARI, 2002, p. 21).

Desde sua gênese, o cruzamento da psicanálise com a literatura tem sido esclarecedor. Pela prática literária, clarificaram-se pontos obscuros da psicanálise. É mais simples entender o Complexo de Édipo conhecendo a tragédia de Sófocles, do que sem nunca ter a lido.

Com isso, podemos dizer que aquilo que nos parece poder ser questionado não é o texto literário a partir da Psicanálise, mas seu inverso, a Psicanálise a partir da Literatura. Esse posicionamento acarreta, através do texto literário, um questionamento do saber da Psicanálise, buscando nas palavras dos escritores, aquilo que não alcançamos dizer (VILLARI, 2002, p. 26).

Não se agrega valor descobrindo que um escritor é neurótico ou paranoico, mas em "descobrir o que subjaz ao efeito do texto sobre o leitor em potencial" (GREEN, 1988a, p. 321). Nessa ótica, a obra de Machado de Assis é um grande adendo à teoria 
psicanalítica, uma vez que por de meio de argutas observações da sociedade, o autor travou um amplo diálogo com as forças inconscientes.

Fazia, sem o saber, uma análise dos processos inconscientes que assolam o ser humano no seu dia-a-dia. Das pequenas coisas, das passagens, a princípio inocentes, postulava uma outra interpretação, um outro lado da história, que permanecia subjacente ao discurso imediato, mas que, muitas vezes, aludia à presença, sempre insidiosa, do inconsciente (FREITAS, 2001, p. 53).

Assim, Machado, por querer sempre encontrar as motivações interiores, "é um psicanalista - é o pensamento psicanalítico existindo porque a dúvida existe. Machado tinha o pensamento psicanalítico, anterior à própria psicanálise" (FREITAS, 2001, p. 70). Como complementa Dante Moreira Leite,

Às vezes, no entanto, a ficção machadiana procura outro nível, que já não é o da introspecção, vale dizer, atinge os impulsos menos conscientes, a região dos abismos inconscientes e irracionais. Ao contrário do que parece à primeira vista, esses momentos são mais ou menos raros em Machado de Assis, porque, quase sempre, a sua necessidade de encontrar uma explicação racional acaba por trazer o conflito ao nível consciente e aí encontrar um jogo de impulsos antissociais e imposições da vida coletiva (LEITE, 2002, p. 259).

Aqui jaz a questão principal do conto. Como ocorre o confronto da pulsão de morte em relação aos desígnios da sociedade? No conto, se traz de uma forma consciente a pulsão inconsciente. Talvez seja um pouco estranho pensar na teoria pulsional aliada à literatura, quando nem na psicanálise essa teoria é unânime, sendo continuamente reorganizada.

O instinto da morte é um conceito rejeitado por muitos dos mais entusiastas adeptos da teoria freudiana (como o próprio Freud observou em seu último livro) [...] Contudo, mesmo se rejeitarmos a teoria, por não se ajustar aos fatos de qualquer maneira útil e operante, não poderemos deixar de notar sua grandeza, sua trágica coragem final, aquiescente ao destino. As ideias do princípio da realidade e do instinto de morte constituem o coroamento da especulação mais ampla de Freud sobre a vida humana. Sua qualidade poética é característica do sistema de Freud e das ideias que gerou para ele (TRILLING, 2015, p. 85).

Inicialmente, havia várias pulsões distintas que foram reduzidas a duas: pulsão de vida e pulsão de morte. Mas, seja qual for o estágio de desenvolvimento do conceito uma 
característica é essencial: a pulsão é uma fonte de energia corporal que estimula o funcionamento do inconsciente. A primeira conceituação específica para a pulsão de morte ocorreu em Além do princípio do prazer (1920), de Freud. Atualmente é uma das formulações mais contestadas na psicanálise por seu caráter abstrato e de difícil aplicação clínica. De uma maneira simplificada, na gênese dessa conceituação as pulsões anteriores estariam essencialmente ligadas à dinâmica do prazer, ou seja, a uma busca do gozo e a evitação do desprazer. Porém, um problema de ordem prática se impôs: o que justificaria a tendência observada nos pacientes pela compulsão à repetição nas neuroses de guerra e no masoquismo?

Para responder essa pergunta, a teoria em que Freud se baseava até então era insuficiente. Por esse motivo, o famoso psicanalista compôs outro tipo de pulsão que não estaria tão ligado ao gozo: a pulsão de morte. Nesta nova postulação, a busca pelo prazer agiria mais fortemente nas pulsões de vida e em comparação a pulsão de morte agiria mais o princípio do Nirvana:

O fato de havermos reconhecido como tendência dominante da vida psíquica, talvez da própria vida dos nervos, o esforço de diminuir, manter constante, abolir a tensão interna dos estímulos (o princípio do Nirvana, na expressão de Barbara Low), tal como se exprime no princípio do prazer - é um dos nossos mais fortes motivos para crer na existência de instintos de morte (FREUD. 2010, p. 228).

O princípio do Nirvana, também conhecido como o "princípio de inércia neuronal", sugere um desinvestimento absoluto por parte do sujeito. Ou seja, um desapego de todas as coisas do mundo. Entretanto, a pulsão de morte não pode ser reduzida a este princípio, isto por que as pulsões não foram um todo único. De fato, estão em profunda imbricação, tornando-se complicado divisar o que é específico da pulsão de vida e o que é da pulsão de morte.

Ademais, o uso do conceito também tem o escopo expandido por teorizações posteriores. Por exemplo, em $O$ mal-estar da civilização (1930), Freud trabalhou as reverberações da pulsão na cultura moderna, o que abriu espaço para uma perspectiva sociológica, antropológica, aliadas à psicanálise. De fato, a pulsão foi tão retrabalhada teoricamente e tornou-se tão ampla que apontar uma definição unívoca é um trabalho hercúleo. Há analistas que relacionam a pulsão com o narcisismo e uma agressividade direcionada a objetos exteriores, enquanto outros preferem focar no masoquismo como manifestação essencial da pulsão de morte. É por esse motivo que algumas formulações 
podem acabar contradizendo as outras, como a caracterização de Luiz Alfredo GarciaRoza em oposição a de Freud:

Se entendermos o desejo como pura diferença, o projeto de Eros seria o da eliminação das diferenças e, portanto, do desejo, numa indiferenciação final que é a humanidade. A pulsão de morte enquanto potência destrutiva (ou princípio disjuntivo) é o que impede a repetição do "mesmo", isto é, a permanência das totalidades constituídas, provocando a emergência de novas formas. Neste sentido, contrariamente à ideia da pulsão de morte como retorno às formas anteriores, temos a pulsão de morte concebida como potência criadora, posto que impõe novos começos ao invés de reproduzir o mesmo. A função conservadora estaria do lado de Eros, enquanto que a pulsão de morte seria a produtora de novos começos, verdadeira potência criadora (GARCIA-ROZA, 1995, p. 163).

Assim, Eros (ou a pulsão de vida) seria mais adequado ao princípio do Nirvana, enquanto Tanatos (ou a pulsão de morte) exerceria a função de movimentar o inconsciente. Afinal, não é uma ideia sem mérito prático, se pensarmos como um confronto com a morte e a dor podem abrir novas perspectivas artísticas e culturais. Como se diz nos ditados populares é na dor que se produzem as mais belas poesias.

No pensamento metódico de Freud não poderiam faltar diferentes pontos de vista sobre a mesma questão. Então, quando começou a teorizar sobre a morte, naturalmente, questionou-se também sobre a vida e a imortalidade. Diversas concepções sobre a imortalidade foram esboçadas, havendo três abordagens principais: 1) Biológica; 2) Espiritual; 3) Artística. Para este artigo, a última é a mais essencial, e aqui é elaborado, pois é por meio da imortalidade que Machado trabalha a pulsão de morte.

A primeira abordagem é delineada por Freud nos textos "Para introduzir o narcisismo" (1914) e "Além do princípio do prazer" (1920): quando se expõe a ideia de imortalidade biológica, realizada pelo ato da reprodução. Como ressalta André Green:

Foi dito que a "invenção" da sexualidade e da morte eram solidárias. Com efeito sem indiferenciação sexual - na ausência de "sexão" - a cisão indefinidamente repetida do mesmo organismo desenha uma figura de imortalidade. Mas pode-se também afirmar num sentido totalmente outro, que quando o indivíduo morre, uma parte dele terá sobrevivido pelo patrimônio que terá transmitido a sua descendência. Se for necessário que a essa se junte a do parceiro do outro sexo, algo dele, no entanto, se transmite, tendo migrado para um outro ser. Imortalidade relativa, portanto, mas assim mesmo imortalidade, pelo menos no espaço de uma geração (GREEN, 1988, p. 279-280). 
A segunda abordagem pode ser observada no texto Considerações atuais sobre a guerra e a morte (1915), onde há uma famosa exclamação: "na escola psicanalítica pudemos arriscar a afirmação de que no fundo ninguém acredita na própria morte; ou, o que vem a significar o mesmo, que no inconsciente cada um de nós está convencido de sua imortalidade" (FREUD, 2010a, p. 230). Porém, da afirmação de que não podemos vislumbrar a própria morte para assumir isto como uma figura de imortalidade há um salto lógico não explicado: se não é possível ter consciência da própria morte, há como efetivamente ter consciência da imortalidade?

Estar privado de qualquer representação da morte e se crer imortal só são equivalentes na aparência. Se a morte não tem representante no inconsciente, este não pode aspirar à imortalidade. Esta recusa que exclui a consciência da morte não se formula em relação à sua possibilidade, e muito menos em relação à sua inelutabilidade (GREEN, 1988, p. 281).

A explicação está em um texto anterior, Totem e Tabu (1913), que faz referência à imortalidade da "alma”. Como a morte de nossos parentes não suprime as lembranças que temos deles, e uma vez que elas ainda nos visitam nos sonhos e nos devaneios, há de haver algo além do corpo. Ou seja, uma alma. Cabe ressaltar que isso não significa que Freud provou a existência da alma em si, mas apenas que expôs uma razão da crença e uma possível origem do conceito de alma, além das implicações que criamos a partir dela, sejam consciente ou inconscientemente. Por esse motivo, em Totem e Tabu há o mesmo argumento do texto de 1915. Portanto, o corpo dos falecidos trouxe tanto a ideia de alma quanto a crença na imortalidade (FREUD, 2010a, p. 239). Sendo assim, como não podemos vislumbrar a própria morte e vemos que os outros retornam, por analogia somos também imortais. Não nos vemos mortos, porque retornaremos.

Recapitulando, é possível observar duas concepções para a imortalidade: a visão dela como movimento biológico para a perpetuação da espécie e a imortalidade pela crença na alma. Há por fim, a terceira maneira proposta por Freud que é a imortalidade por meio da arte, mais especificamente pela literatura. No texto Considerações atuais sobre a guerra e a morte (1915) discute-se que por conta de nossa vida efêmera buscamos a imortalidade na ficção literária (FREUD, 2010a, p. 232). Vivemos muitas vidas quando lemos: "No reino da ficção encontramos a pluralidade de vidas de que temos necessidade. 
Morremos na identificação com um herói, mas sobrevivemos a ele e já estamos prontos a morrer uma segunda vez com outro, igualmente incólumes" (FREUD, 2010a, p. 233).

Porém, como a literatura não é um ato de mão única, duas formas se implicam: a imortalidade pela leitura e a imortalidade pela escrita. Esta segunda concepção foi exposta em $O$ inquietante (1919) pela figura do duplo escritor/leitor. Em outras palavras, ao escrevermos podemos fazer o leitor viver conosco ou com um duplo de nós mesmos. Essa questão se aprofunda quando se trata de uma obra autobiográfica ou de autoficção. André Green explica a figura da imortalidade pelo duplo:

Aqui não se trata mais da imortalidade da sexualidade por vocação biológica, nem da ausência de representação da morte na vida psíquica inconsciente, mas de uma crença do Eu que pode, num determinado momento, tornar-se consciente sob a cobertura da ficção. [...] É deste ponto de vista que se pode realmente falar de imortalidade, isto é, de uma autêntica recusa da morte no seio de um $\mathrm{Eu}$ que se sabe mortal, com seu duplo que se recusa a admitir a fatalidade do término de sua existência (GREEN, 1988, p. 283).

Estas concepções propostas pelos teóricos, apesar de plausíveis para os humanos, são insuficientes em relação aos personagens literários, ainda mais o deste conto, que é imortal. As duas perspectivas em relação à imortalidade literária pela leitura e escrita se aplicam, no entanto, em certo nível, também podem dizer respeito a qualquer trabalho ficcional de sucesso. O que há de figura da imortalidade para os seres humanos, há também para os personagens literários e um pouco mais.

Assim, Capitu, apesar de ter morrido, vive muito mais do que as páginas de Dom Casmurro (como objeto físico). O livro pode ser reproduzido em tiragens potencialmente infinitas, ou, o personagem em si tem filhos e mais filhos. Como por exemplo, o Coronel Aureliano Buendía, de Cem anos de Solidão, com 17 filhos, todos também nomeados Aureliano. Mas, a imortalidade na diegese abre outras questões: os personagens podem ser realmente imortais se não há consciência da morte e da imortalidade, ou, se no mundo ficcional, esta consciência é possível? Qual a consequência do fato para a psique do personagem e como ela é esteticamente trabalhada?

Pode parecer um truísmo, mas quem escreve é humano e, logo, possui um horizonte limitado de experiência. Pois é complicado escrever sobre o que não se pode vislumbrar. Talvez por esse motivo, a resposta para muitos autores que trabalham com a 
temática, incluindo Machado, é parecida: a consciência da imortalidade é possível à duras penas, já a da própria morte é impossível.

Um paralelo com a realidade contemporânea pode ajudar a entender como se dá o progresso para a consciência da imortalidade nos personagens. Isto é possível, ao observamos as pessoas temerárias, que parecem agir como se não existisse a morte. Neste caso, de acordo com André Green, a ideia da imortalidade viria por um inchaço do ego, um forte desejo narcísico de se afirmar.

$\mathrm{O}$ não-reconhecimento da morte no inconsciente escolheu como domicílio o Eu. Mas como o Eu é também consciente - necessidade obrigada - a instância garantidora da racionalidade que se sabe mortal pela sua relação com a realidade externa, carrega nas suas dobras um forro megalomaníaco, pronto para se inchar até eclipsar o outro, às vezes pelo inocente prazer da ficção, em outras pela sustentação da fé (GREEN, 1988, p. 285).

Para este homem que chamamos de temerário, o prazer ocorre em dois momentos: no fugaz fluxo de adrenalina e no desejo narcísico de ser único. Ou seja, ser a única pessoa no mundo que não pode morrer. Que enganou a morte e continuará a enganá-la, ao ter sobrevivido um "racha" ou escalado uma torre de telecomunicações sem equipamentos de segurança.

\begin{abstract}
A imortalidade é um estado de idealização do Eu que sabemos estar, por outro lado, ameaçado na sua existência. [...] A série de figuras que a imortalidade percorre vai da fusão primitiva do jovem Eu com o objeto ao investimento narcisista do Eu, e depois ao investimento do duplo, num movimento evolutivo coerente (GREEN, 1988, p. 295).
\end{abstract}

Então, este homem, com a crença de ser o único imortal por ter sobrevivido a várias situações perigosas, começa a estabelecer-se de acordo com a evolução proposta por André Green. Isto é, se crê imortal e inicia a transposição de sua imagem para a posterioridade. É neste ponto que Robert Craig Jr. vira Evel Knievel ${ }^{2}$. É por esse motivo que não há apenas o ato realizado e a descarga de adrenalina, mas também uma compulsão de gravar vídeos da ação repetidamente, como evidenciados pelos inúmeros vídeos na internet. Há o gozo em mostrar-se ao mundo como imortal. O corpo marcado pelas cicatrizes, ou não, carrega essa narrativa.

2 Famoso motociclista norte-americano que realizava shows performáticos. Entrou no Livro Guiness de Recordes Mundiais como o homem com "mais ossos quebrados" 
De maneira similar, para o personagem do conto a imortalidade pode ser vista como um movimento narcísico. No início da diegese, descobrimos que Ruy de Leão tomou o hábito no Convento de Iguaraçu, onde ficou até ser invadido por holandeses, mas já mostrava antes o desejo de sair do Convento, pois era avesso à vida monástica. Movido pelo desejo trilhou o caminho contrário à vida celibatária, viveu entre os indígenas onde se casou pela primeira vez. Seu sogro, que lhe tinha afeição, quando próximo da morte, mostrou um segredo: um remédio feito por um xamã que imortalizaria quem o bebesse.

Inicialmente Ruy não acreditou no remédio, tanto que o esqueceu até o momento que ficou doente e após beber metade do conteúdo, miraculosamente, recuperou a saúde. É característico que a imortalidade neste caso não tenha vindo de poderes divinos ou acontecimentos mágicos, mas de um ato corporal: a ingestão de um líquido. Assim, o elixir é a pulsão liquefeita, que o estimulou. A partir do momento que o progresso da imortalidade começa a se caracterizar e a fazer seus efeitos, imediatamente angustiou-se. "Moço, perpetuamente moço. A vida do mato começara a aborrecê-lo; ficara ali por gratidão ao sogro; as saudades da civilização vieram tomá-lo" (ASSIS, 2006, p. 890). Após a morte da esposa, Ruy vira cidadão do mundo e o desejo sexual, que já era forte, o domina.

Que o amor, força é dizê-lo, foi uma das causas da vida agitada e turbulenta do nosso herói. Ele era pessoalmente um homem galhardo, insinuante, dotado de um olhar cheio de força e magia. Segundo ele mesmo contou ao filho, deixou muito longe o algarismo don-juanesco das mille e tre (ASSIS, 2006, p. 891-892).

Quando se pensa em uma maneira de observar a pulsão, no trabalho analítico, vários problemas se apresentam. Afinal, a pulsão em si é algo que não se vê, mas sentido por meio das representações. Um dos poucos consensos é que na pulsão de morte a repetição é comum. Mas por que para o personagem do conto essa repetição realizada é a do amor, afinal não estaria o amor mais ligado a uma pulsão de vida? Deve-se notar que o ato de repetir não é o mesmo do que o quê se repete. É possível que a repetição do ato sexual seja uma manifestação da pulsão de vida, mas o ato de repeti-la aponta outro caminho.

A compulsão que afeta o personagem é a busca de Eros. Por ser imortal não é possível perder a vida, mas tem o poder de criá-la? Eros promove uniões, sejam dos corpos ou das almas, ou seja, conectar-se no mundo para criar uma vida significativa. É 
neste sentido que Ruy de Leão é impotente. Sendo o único de sua espécie, não é possível compartilhar sua vida com um companheiro. Talvez por isso, Ruy cogitou, por um momento, dividir a dádiva com "alguma senhora ou homem” (ASSIS, 2006, p. 899), mas não o fez. De fato, fazia juras de amor para as esposas, mas não escolheu alguma para ser imortal junto dele, preferia sofrer sendo único. "A interiorização desta contradição leva a reencontrar em Eros uma dualidade que será o segundo redobramento. Ou seja, a divisão de Eros entre amor de si e amor de objeto e entre conservação de si e conservação da espécie" (GREEN, 1988, p. 104).

A repetição é em parte pela busca de um ato criador e de conexão, mas o ato repetido aponta apenas ao amor de si. Pois prefere manter-se único a compartilhar a posição privilegiada. Como vimos anteriormente, Luiz Alfredo Garcia-Roza expôs que na pulsão de morte há também um aspecto criador. O contrário também é verdadeiro, há destruição em Eros.

Retorno ao repouso original. Freud busca na extinção da tensão advinda após o ato sexual um argumento a favor de sua hipótese, atribuindo a esta extinção o caráter de ser finalidade do ato sexual: o impulso pulsional "seria" a própria "função preliminar, destinada a preparar a excitação para sua eliminação final no prazer da descarga" (MARTINS, 2009, p. 53).

Ao mesmo tempo em que busca algum tipo de conexão, Ruy de Leão busca a "petite mort" do orgasmo. Eros paradoxalmente é a criação de vida e de morte. Nesta perspectiva, o imortal é também incapaz do gozo como um estado de extinção. Não pode ser mortal, ou sentir-se mortal, nem por um instante. A contradição do personagem é buscar ao mesmo tempo manter-se único e morrer como todos os outros. Não há outra opção para ele, senão a repetição, pois a pulsão não pode ser plenamente satisfeita.

A suposição de que a atividade sexual é natural e que por esta razão daria lugar à satisfação da pulsão é, como já vimos, ilusória. [...] No entanto, pode ocorrer que a atividade sexual, precisamente por ser claramente sexual, deixe mais fortemente patente que a satisfação é impossível, fazendo com que se multipliquem as experiências sexuais numa busca infindável de um gozo que jamais será obtido. Um Casanova, com suas frequentes aventuras sexuais, está menos insatisfeito do que o artista em sua atividade criadora, o intelectual em sua produção científica ou o religioso em sua busca de Deus? Não seriam todas estas buscas igualmente infrutíferas, se admitimos que todas elas são movidas pela pulsão, cujo alvo é precisamente manter-se como Konstante Kraft? (GARCIA-ROZA, 1995, p. 139). 
A imortalidade que deseja é, na verdade, diferente da que possui. O que busca é um desejo narcísico, a "aspiração a uma totalidade auto-suficiente e imortal onde o autoengendramento é a condição, morte e negação da morte ao mesmo tempo" (GREEN, 1988, p. 142).

O fim último do narcisismo é o apagamento dos traços do Outro no Desejo do Um. É, portanto, a abolição da diferença primeira, a do Um e do Outro. Mas o que significa esta abolição no retorno ao regaço materno? O que o narcisismo primário visa pela abolição das tensões ao nível zero é, ou a Morte, ou a imortalidade, o que dá na mesma (GREEN, 1988, p. 211).

No fundo, seu desejo não era apenas ser único, mas que todos sejam iguais a ele. À sua imagem e semelhança. Mas ao contrário, a imortalidade que recebeu evidenciou, de forma gritante, as diferenças entre ele e o resto da humanidade. A morte que chega a todos e une a todos foi negada, assim como a "petite mort". Infelizmente, seu futuro não pode ser como o de Don Juan, cujas repetições findam, por isso continuou e esta situação teve consequências, "acostumou-se, e enfarou-se, que era outro fenômeno na vida dele. Enfarava-se dos ofícios. As longas solidões do mar alargaram-lhe o vazio interior" (ASSIS, 2006, p. 894-895).

Como esse vazio não era preenchido por nada, tentou o suicídio: “"Filho', diziame ele, contando-me o episódio; 'dei seis golpes, cada um dos quais bastava para matar um homem, e não morri'. Desesperado, saiu de casa e atirou-se ao mar. O mar restituiuo a terra. A morte não podia aceitá-lo: ele pertencia à vida por todos os séculos” (ASSIS, 2006, p. 896). Não havia perspectiva de mudança e isso o levou ao estado de melancolia, um dos domínios da pulsão de morte. "A alma de meu pai chegara a um grau de profunda melancolia. Nada o contentava; nem o sabor da glória, nem o sabor do perigo, nem o do amor. [...] Vegetava consigo; triste, impaciente, enjoado" (ASSIS, 2006, p. 899). A vida eterna era um dos piores suplícios, vivia em um tédio absurdo e refletindo sobre a própria vida, aconselhou o filho que não desejasse tal maldição.

Era-lhe forçoso repeti-las, sem trégua, sem um respiro ao menos, porquanto, a experiência não the podia valer contra a necessidade de agarrar-se a alguma cousa, naquela passagem rápida dos homens e das gerações. Era uma necessidade da vida eterna; sem ela, cairia na demência. Tinha provado tudo, esgotado tudo; agora era a repetição, a 
monotonia, sem esperança, sem nada. Tinha de relatar a outros filhos, vinte ou trinta séculos mais tarde, o que me estava agora dizendo; e depois a outros, e outros, e outros, um não acabar mais nunca (ASSIS, 2006, p. 900).

Por meio de Eros não conseguia passar a imortalidade aos filhos, não podia ter companheiros, e no fundo, nem o queria. Mas, tinha que repetir-se, tanto para manter a sanidade, quanto por pressão social. A vida em sociedade não foi designada para os que vivem eternamente, como visto pela própria experiência que teve com a Inquisição. Ou, se pensarmos em outra obra, o caso dos Struldbrug, ostracizados em As viagens de Gulliver. Adolfo Hansen resume o suplício de Ruy:

Nos diversos momentos dos seus 255 anos, variam enormemente as pessoas e as experiências; no entanto, em todas as situações que vive, ano após ano, entre 1639 e 1855, sempre se lê a mesma história básica. Como se, vivendo o impossível da imortalidade, a cada nova experiência estivesse condenado a efetivamente viver as possibilidades restritas de uma vida só mortal, repetindo na longa extensão da sua as mesmas poucas experiências da vida breve de todos, o amor, a aventura e a intriga (HANSEN, 2006, p. 60).

Nesta ótica, por ter de viver repetidamente uma vida mortal também não era possível "mostrar-se" imortal. Porém, no início do conto sabemos que o imortal acabou morrendo, como isto é possível? Haveria então uma resposta ao dilema da imortalidade?

Ruy, seguindo um princípio homeopático, resolveu o problema: "Similia similibus curantur. Bebera o resto do elixir, e assim como a primeira metade lhe dera a vida, a segunda dava-lhe a morte. E, dito isto, expirou" (ASSIS, 2006, p. 900). Dessa forma, insinua-se que talvez esta seja uma história inventada para vender produtos homeopáticos, o que é plausível, mas a frase final subverte essa interpretação:

A suspeita de que ele apenas quis propagar a homeopatia entrou em alguns cérebros, e não era inverossímil. Dou este problema aos estudiosos. Tal é o caso extraordinário, que há anos, com outro nome, e por outras palavras, contei a este bom povo, que provavelmente já os esqueceu a ambos (ASSIS, 2006, p. 900).

Portanto, Dr. Leão é Ruy de Leão, provavelmente ainda de posse do elixir para que não haja ninguém como ele. Nada mudou, o fato de contar sempre a mesma história é outro indicativo da repetição. Repete sua narrativa para ter um prazer narcísico secundário, já que o primário não é possível. Ademais, em um pano de fundo metatextual, 
aponta também a outro conto de Machado de Assis com a mesma história: Rui de Leão, publicado 10 anos antes. Com isso, o imortal poderia ser na verdade Machado de Assis, contando a mesma história sempre.

Em conclusão, pode-se dizer que o conto antecipa as proposições da pulsão de morte e imortalidade da psicanálise, trabalhando simultaneamente as três formas apontadas pela teoria. A imortalidade mostra-se fruto de um profundo desejo narcísico, que só pode ser repetidamente realizado e desfrutado pela palavra, uma vez que na vida prática sua existência deve ser dissimulada.

\section{REFERÊNCIAS}

ASSIS, Machado de. Obra completa. Vol. II. Rio de Janeiro: Nova Aguilar, 2006.

FREITAS, Luiz Alberto Pinheiro de. Freud e Machado de Assis: uma interseção entre psicanálise e literatura. Rio de Janeiro: Mauad, 2001.

FREUD, Sigmund. Obras completas volume 14: História de uma neurose infantil ("O homem dos lobos"), Além do princípio do prazer e outros textos. [1917-1920]. São Paulo: Companhia das Letras, 2010.

. Obras completas volume 12. Introdução ao narcisismo, ensaios de metapsicologia e outros textos. [1914-1916]. São Paulo: Companhia das Letras, 2010a.

GARCIA-ROZA, Luiz Alfredo. Introdução à metapsicologia freudiana. v. 3. Rio de Janeiro: Jorge Zahar, 1995.

GREEN, Andre. Narcisismo de vida, narcisismo de morte. Tradução de Claudia Berliner São Paulo: Escuta, 1988.

. Sobre a loucura pessoal. Tradução Carlos Alberto Pavanelli. Rio de Janeiro: Imago, 1988a.

HANSEN, João Adolfo. O Imortal e a Verossimilhança. In: Teresa revista de Literatura Brasileira [6/7]. São Paulo, 2006. p. 56-78.

LEITE, Dante Moreira. Psicologia e Literatura. 5 Ed. São Paulo: Editora Unesp, 2002.

MARTINS, André. Pulsão de morte? Por uma clínica psicanalítica da potência. Rio de Janeiro: UFRJ, 2009.

TRILLING, Lionel. A imaginação liberal: ensaios sobre a relação entre literatura e sociedade. Tradução de Cecília Prada. São Paulo: É Realizações, 2015. 
Revista Água Viva

ISSN 1678-7471

VILLARI, Rafael Andrés. Literatura e psicanálise: Ernesto Sábato e a melancolia. Florianópolis: Editora da UFSC, 2002. 